\title{
New developments in the treatment of hypoactive sexual desire disorder - a focus on Flibanserin
}

\author{
This article was published in the following Dove Press journal: \\ International Journal of Women's Health \\ 10 April 2017 \\ Number of times this article has been viewed
}

\author{
Christopher J Jayne \\ Michael J Heard ${ }^{2}$ \\ Sarah Zubair ${ }^{3}$ \\ Dustie L Johnson ${ }^{4}$ \\ 'Greater Houston Urogyn, \\ 2Department of Ob/Gyn, St Joseph \\ Medical Center, The Heard Institute, \\ ${ }^{3}$ Department of Natural Sciences, The \\ University of Houston - Downtown, \\ Houston, ${ }^{4}$ Reproductive Solutions Inc., \\ Midland, TX, USA
}

\begin{abstract}
The objective of the authors is to highlight the historical complexities for the diagnosis and treatment of hypoactive sexual desire disorder (HSDD) with a focus on Flibanserin. A systematic review of the medical literature published in PubMed using the search terms HSDD and Flibanserin was conducted. Each author reviewed the results of the systematic review for articles to include in this study. HSDD is defined as a persistent or recurrent deficiency or absence of sexual fantasies and desire for sexual activity causing marked distress or interpersonal difficulty that is not better accounted for by another diagnosis. Until 2015, only homeopathic products and off-label use of prescription medications were medical treatment options for women with HSDD. Flibanserin, approved by the US Food and Drug Administration (FDA) in 2015, is the first to target female HSDD in premenopausal women. Flibanserin is a centrally acting nonhormonal oral medication taken once daily that affects serotonin, dopamine and norepinephrine levels, the key neurotransmitters in the biology of desire. Understanding prescribing guidelines and awareness of black box warnings is paramount for prescribers. Adherence to proper oversight will ensure Flibanserin can fulfil an unmet need for an FDA approved prescription medication for the treatment of HSDD in premenopausal women.
\end{abstract}

Keywords: flibanserin, hypoactive sexual desire, women's sexual health

\section{Introduction}

Sexual health is defined in part by the World Health Organization as a state of physical, emotional, mental, and social well-being in relation to sexuality; not merely the absence of disease, dysfunction, or infirmity. ${ }^{1}$ The definition is based on landmark publications from sexual health researchers over the last century. Once normal is defined, abnormal can then be recognized, defined and ultimately treated.

Diminished sexual desire is the most widely recognized sexual complaint reported in epidemiologic studies. ${ }^{2-4}$ Hypoactive sexual desire disorder (HSDD) is the formal term used when diagnosing and treating women with various types and causes of diminished sexual desire. Despite over three decades since its definition and multiple changes in an attempt to improve the accuracy of the diagnosis, established treatment paradigms are lacking.

Medical treatments for HSDD have relied on homeopathic products and off-label use of prescription medications. This has been due in part to a poor understanding of the biology of desire. In 2015, the US Food and Drug Administration (FDA) approved Flibanserin for the treatment of HSDD in premenopausal women. Flibanserin is a centrally acting receptor agonist and antagonist affecting serotonin, dopamine and norepinephrine activity. ${ }^{5}$ These neurotransmitters are believed to be crucial in the biology of desire. Flibanserin's use has the potential to be the cornerstone in treatment paradigms for premenopausal women with HSDD.
Correspondence: Christopher J Jayne St Joseph Medical Center, 1315 St Joseph Parkway Suite, 1306 Houston, TX 77002, USA

$\mathrm{Tel}+\mathrm{I} 8329248788$

Email cjayne.ghu@gmail.com
International Journal of Women's Health 2017:9 17|-178

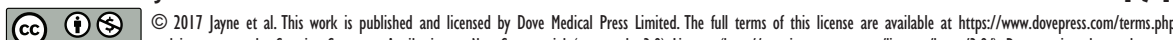
cc) hereby accept the Terms. Non-commercial uses of the work are permitted without any further permisision from Dove Medical Press Limited, provided the work is properly attributed. For permission for commercial use of this work, please see paragraphs 4.2 and 5 of our Terms (htpps://www.dovepress. com/terms.php). 


\section{Human sexual response}

Theoretical models to define human sexual response have advanced over time. In the 1920s, Sigmund Freud described the sexual response as a complicated sequence of related events ultimately resulting in the execution of the sex act. ${ }^{6}$ In the 1960s, William Masters and Virginia Johnson proposed a four-stage linear model to characterize the physical and emotional changes that occur when a person engages in sexual activities. ${ }^{7}$ The duration and characteristics of each stage is unique to a person, and vary between men and women. The Masters and Johnson model starts with excitement, whereby physiologic signs of arousal are noticed, such as an increase in heart rate, increased blood flow to the genitals and faster breathing. The excitement stage can last from a few minutes to a few hours.

Excitement is then followed by plateau. The duration of this stage is less than the former; however, it is characterized by an increase in the physiologic responses that carry over from excitement. The heightened physiologic response then leads to the third stage, orgasm. The duration of this stage is the shortest of all - only a few seconds. In this stage, changes from the initial stages are at their peak, which eventually results in the release of sexual tension and procession to the final stage, resolution.

During resolution, all heightened conditions return back to normal and a feeling of satisfaction, fatigue and exhaustion is normal. Groundbreaking, this model for the human sexual response was revered. Some researchers, however, saw room for improvement, mainly because the sexual response cycle lacked a fundamental aspect of human sexuality, a psychological component. One such researcher was Helen Kaplan who, in 1970s, modified the sexual response linear paradigm by adding the desire stage and effectively compressing the four-stage model into a three-stage process: desire, arousal and orgasm. ${ }^{8,9}$

In the desire stage, a person is psychologically priming for sex. This is done before any physiologic changes are seen. Similar to the four-stage model, Kaplan's second stage is excitement. This is characterized by physical arousal which may result in an erection for men or vaginal lubrication for women. Orgasm, the last stage, includes release of sexual tension and a general feeling of satisfaction. A key point of Kaplan's model was to emphasize the fact that sexual dysfunctions can occur in any of the three stages, including the psychological stage of desire, resulting in the need for various interventions for each type of dysfunction.

In the 1980s Harold Lief held similar views as Kaplan, and independently proposed a five-stage linear model where desire is followed by arousal then vasocongestion, orgasm and ultimately satisfaction. ${ }^{10}$ Desire represented a notion to engage in sexual activity, with arousal being a physical awareness of changes associated with anticipation of sexual activity. Vasocongestion referenced the engorgement response in the sexual organs. Orgasm was a systematic release of sexual tension and satisfaction denoted by the global sense of wellbeing at the completion of sexual activity. Despite being linear it was coined the desire, arousal, vaso, congestion, orgasm, satisfaction cycle. Also similar to Kaplan he emphasized a multifaceted approach when treating sexual disorders.

In the 1990s Beverly Whipple proposed a four-stage model for sexual response that progressed in a cyclic fashion: seduction, sensations, surrender, and reflection. ${ }^{11}$ Until this time, all models proposed for human sexual response were linear. Each stage in the Whipple model encompasses aspects from the multistage models proposed by earlier researchers. Seduction involves desire, sensations encompass excitement and plateau, surrender is related to orgasm and reflection is akin to resolution. This model emphasizes the positive reinforcement effect of sex, such that each positive sexual experience reinforces a desire for more sexual experiences.

In the early 2000s, Rosemary Basson built on Whipple's cyclic model by expanding on sexual desire and emphasizing an emotional satisfaction aspect to sex. ${ }^{12}$ In addition her model was the first to explain a women's sexual response specifically. She described a woman's sexual response in dynamic nonlinear terms whereby a woman's sexual response ultimately results in satisfaction. She described a process where a woman can enter the sexual response cycle at various stages as each stage can affect another in either direction. The goal in her model is satisfaction, both physical and emotional and is determined by the individual. Similar to earlier models, the Basson model acknowledged multiple entry points for the treatment of sexual dysfunctions.

\section{Hypoactive sexual desire disorder}

The formal history defining low sexual desire originated in the diagnostic classification system of the American Psychiatric Association. The Diagnostic and Statistical Manual of Mental Disorders (DSM) in 1980 first published its definition with changes occurring throughout updated publications. DSM-II in 1980 defined Inhibited Sexual Desire. The term HSDD was first introduced in the DSM III-R in 1987. It was defined as persistently or recurrently deficient or absent sexual fantasies and desire for sexual activity. The definition of HSDD has developed over time 
to address current clinical information in an attempt to better diagnose and treat this condition.

Between 1994 and 2000 DSM-IV further supplemented the original definition with added criteria of the disorder requiring marked distress or interpersonal difficulty and not better accounted for by another sexual disorder and not due to the direct effects of drug abuse or a general medical or psychologic condition. HSDD could further be classified as primary or secondary, acquired or lifelong, and generalized or situational. In the 2013 DSM-5 edition, disorders of desire and arousal were joined into one classification titled female sexual interest/excitement and arousal disorder (FSIAD). The DSM-5 classification of FSIAD requires that the lack of sexual interest must cause distress $75 \%-100 \%$ of the time with $>6$ months of persistence. Regardless of the adjustment in the DSM terminology from HSDD to FSIAD, HSDD still exists as a center part of FSIAD.

\section{Biology of desire}

The complexities of the human sexual response rival those of any physiologic response in medicine. Testosterone, often thought of as a male hormone, is vital in normal sexual function in women. Free testosterone is crucial as it affects key receptors both centrally and peripherally to promote a normal sexual response and desire. For women, testosterone is primarily produced from precursor hormones produced in the adrenal glands with final conversion in various locations including the adrenals, ovaries and peripheral tissue. ${ }^{13}$ Although precursor hormones may also promote normal sexual responses, testosterone has the greatest effect. In women it acts centrally to promote desire as well as peripherally in the vulva and vagina to facilitate arousal by optimizing blood flow and facilitating lubrication. ${ }^{14}$

Estrogen is another key sexual hormone in women. Identified in three major forms, estrone, estradiol and estriol, estrogen is also derived from precursor hormones with a central and peripheral effect promoting the sexual response and desire in women. ${ }^{15,16}$

Centrally estradiol promotes sexual desire such as testosterone, it acts peripherally in the vulva and vagina to promote blood flow, lubrication and the arousal response. ${ }^{17-20}$

Nitric oxide is a chemotactic agent that can influence the sexual response. It is a potent vasodilator throughout the body and facilitates blood flow and lubrication to the vulva and vagina. Optimizing blood flow and lubrication to the sexual organs promotes the arousal response facilitating a pleasurable experience. This then has the potential to indirectly affect desire.
Neurotransmitters are chemical messengers that convey signals from one neuron to the next. Dopamine, norepinephrine and serotonin are three important centrally acting neurotransmitters of the limbic system vital for normal sexual health and associated with sexual desire. ${ }^{21,22}$ Dopamine positively influences pleasure and reward pathways in the brain. Sexual activity involving desire is a pleasurable activity rewarded with satisfaction when all goes well. Thus increasing dopamine levels has the potential to increase sexual desire. ${ }^{23}$ Norepinepherine is another important neurotransmitter for sexual desire and is associated with motivation. It has been shown to be elevated during sexual arousal and orgasm, both of which are motivating factors that can positively affect desire. ${ }^{24}$ Serotonin is an inhibitory neurotransmitter for sexual desire and has been shown to be activated during periods of sexual inhibition and to restrict excitatory systems. ${ }^{21,25,26}$

\section{Homeopathic options}

In the absence of an FDA approved medication to treat sexual dysfunction, homeopathic or alternative products have been promoted as a treatment option based on an understanding of the biology of desire. The FDA does not regulate alternative products such as herbal or nutritional supplements, so while proprietary alternative product companies can claim their products enhance the sexual response in women, they are not required to publish studies to support such claims. That said, the public at large is eager to accept an alternative option especially when no other options exist. Table 1 lists homeopathic options, their ingredients and proposed effect on sexual response.

\section{Off-label prescription drug therapies}

It is common practice to use prescription medications for off-label indications. This is especially true for conditions without any FDA approved medical treatment options. Thus it should come as no surprise that various prescription medications have been used in an attempt to treat HSDD (Table 2). A combination therapy of esterified estrogen and methyltestosterone is approved by FDA to treat hot flashes and is also commonly used off-label to treat HSDD. ${ }^{27}$ Multiple studies report improved sexual desire suggesting it is a viable treatment option for HSDD. ${ }^{28-32}$

Bupropion is a norepinephrine and dopamine reuptake inhibitor approved by the FDA for the treatment of depression. Bupropion has been studied for its effect on sexual function and HSDD with results showing improved sexual desire in depressed patients as well as improved desire in 
Table I Homeopathic options for the treatment of HSDD

\begin{tabular}{|c|c|c|c|}
\hline $\begin{array}{l}\text { Herbal } \\
\text { supplement }\end{array}$ & Ingredients & $\begin{array}{l}\text { Proposed effect on sexual } \\
\text { response }\end{array}$ & References \\
\hline Zestra & $\begin{array}{l}\text { Borage seed oil, evening primrose oil, angelica extract, coleus } \\
\text { extract, vitamin C, vitamin E }\end{array}$ & $\begin{array}{l}\text { Increased genital sensitivity and } \\
\text { lubrication }\end{array}$ & 52 \\
\hline Alura & $\begin{array}{l}\text { Purified water, propylene glycol, hydroxyethylcellulose, } \\
\text { L-arginine, menthol, citric acid }\end{array}$ & $\begin{array}{l}\text { Increased genital sensitivity and } \\
\text { lubrication }\end{array}$ & 53 \\
\hline ProSensual & Natural mint, orange, clove oil and soy-based ingredients & Increased sensation and lubrication & 54 \\
\hline $\mathrm{K}-\mathrm{Y}$ & $\begin{array}{l}\text { Purified water, glycerin, hydroxyethylcellulose, chlorhexidine } \\
\text { gluconate, gluconolactone, methylparaben, sodium hydroxide }\end{array}$ & Increased sensation and lubrication & 55 \\
\hline ArginMax & $\begin{array}{l}\text { L-arginine, gingseng, ginkgo, damiana, calcium, iron, vitamins } \mathrm{A} \text {, } \\
\mathrm{C} \text {, and } \mathrm{E}, \mathrm{B} \text {-complex vitamins, zinc }\end{array}$ & Increased sensation and lubrication & 56 \\
\hline Avlimil & $\begin{array}{l}\text { Genistein soy isoflavones, black cohosh root, organic sage and } \\
\text { raspberry leaf, organic cayenne pepper, damiana leaf, ginger } \\
\text { root, licorice root, valerian root }\end{array}$ & Increased sensation and lubrication & 57 \\
\hline
\end{tabular}

Abbreviation: HSDD, hypoactive sexual desire disorder.

patients with serotonin specific reuptake inhibitor induced HSDD. ${ }^{23,33,34}$ These results have led to its off-label use in the treatment of HSDD.

Sildenafil is a phosphodiesterase type 5 (PDE5) inhibitor. Inhibition of PDE5 promotes vasodilation via the sustained effects of nitric oxide in the vascular system throughout the body including the vulva and vagina. FDA approved for the treatment of erectile dysfunction and pulmonary hypertension, sildenafil has been studied for off-label use in women with HSDD with minimal benefit. . $5,26,35$

Buspirone is an azapirone, a class of drugs commonly used as anti-anxiety agents. It is an FDA approved drug for the treatment of general anxiety and binds to both serotonin and dopamine receptors in the brain. It has been studied for its potential to affect sexual function and possible off-label use in HSDD with some promise..$^{36-38}$

\section{Flibanserin}

Flibanserin was first studied as a potential antidepressant due to its proposed mechanism of action. Flibanserin is a dynamic compound that affects serotonin, dopamine and norepinephrine activity with affinity for 5-HT1A, 5-HT2A,

Table 2 Off-label prescription medications used for the treatment HSDD

\begin{tabular}{lll}
\hline Drug & Effect on sexual response & References \\
\hline $\begin{array}{l}\text { Esterified estrogen/ } \\
\text { methyltestosterone }\end{array}$ & $\begin{array}{l}\text { Increase in sexual interest } \\
\text { and increase in genital } \\
\text { sensitivity and lubrication }\end{array}$ & $27,28,58$ \\
Bupropion & $\begin{array}{l}\text { Increased sexual interest } \\
\text { Sildenafil }\end{array}$ & $\begin{array}{l}\text { Increased genital sensitivity } \\
\text { and lubrication }\end{array}$ \\
Buspirone & $\begin{array}{l}\text { Increased sexual interest } \\
\text { In, 26,35 }\end{array}$ & 36,38 \\
\hline
\end{tabular}

Abbreviation: HSDD, hypoactive sexual desire disorder.
5-HT2B, 5HT2C and Dopamine D4 receptors in the brain. ${ }^{5,39,40}$ It was initially found to lower serotonin and raise dopamine and norepinephrine activity in the prefrontal cortex in rat studies. ${ }^{41}$ It was advanced to clinical human trials based on an understanding of these neurotransmitters and their role in depression but failed to prove effective in treating depression. ${ }^{42}$ It was, however, noted to improve sexual desire in depressed woman with decreased sexual desire at baseline. ${ }^{43}$ This improvement in sexual desire was felt to be related to Flibanserin's effect on neurotransmitters in the limbic system and this led to a rerouting of the development of the drug as a potential nonhormonal treatment for HSDD. ${ }^{44}$

The results of four phase three and one safety and tolerability trials in premenopausal women initiated by the manufacturer were subsequently published in the Journal of Sexual Medicine from 2011 to 2013 and formed the basis for Flibanserin's FDA approval process. The first phase III trial titled Researching Outcomes on Sustained Efficacy (ROSE) was a multicenter prospective withdrawal study. ${ }^{45}$ Women diagnosed with HSDD via clinical interview in conjunction with a validated sexual health questionnaire who proved compliance with an electronic diary (e-diary) validated to capture sexual health information who were in stable monogamous heterosexual relationships with an otherwise sexually functional partner were enrolled.

Exclusion criteria were exhaustive and included both medical and psychological conditions, various medications, other sexual dysfunctions in addition to HSDD or at the discretion of the investigator. All women received open label flexible dosed flibanserin for 24 weeks. Dosing options were $50 \mathrm{mg}$ nightly, $50 \mathrm{mg}$ twice daily or $100 \mathrm{mg}$ each night. Women were evaluated with the e-diary, validated sexual health questionnaires and direct questions by the investigator 
to track effects on sexual desire and for adverse events. At the completion of the first 24 weeks responders defined as those women having an increase in satisfying sexual events (SSE) of at least two per month or at least four desire days per month were then randomly assigned flibanserin or placebo in a double blind fashion for another 24 weeks.

One hundred sixty-three women were randomized to flibanserin with 146 completing the study and 170 women were randomized to placebo with 146 completing the study. At the completion all women were then followed for 4 weeks to assess efficacy, adverse events and withdrawal events. Overall at the end of the initial open label period $64 \%$ reported they were much or very much improved with improvements noted in SSE and in the validated sexual health instruments. At the completion of the 24-week blinded period. Primary outcomes were assessed using SSE and e-diary with secondary outcomes assessed with validated sexual health questionnaires.

Mean SSE and validated sexual health questionnaire scores did not retain their baseline levels reached at the completion of the initial open label 24 weeks. However, the flibanserin group's scores were significantly better than the placebo group at the completion of the 24-week blinded period. Flibanserin was noted to be well tolerated with the most common adverse events being nausea, somnolence, fatigue, headache, dizziness, irritability and depression. Similar AEs were noted in the second phase of the study with many reported more commonly in the placebo group which had twice the discontinuation rate as the flibanserin group. There were no significant withdrawal symptoms noted.

The Dose Ascending Study over Half-a-Year (DAISY) was published in 2012. ${ }^{46}$ This randomized placebo controlled 24-week prospective double blinded multicenter trial compared placebo to flibanserin $25 \mathrm{mg}$ twice daily, $50 \mathrm{mg}$ flibanserin twice daily and $100 \mathrm{mg}$ nightly for safety and efficacy in premenopausal women diagnosed with HSDD via clinical interview and validated sexual health questionnaire.

Study inclusion and exclusion criteria were similar to the ROSE trial, such as ROSE, e-diary entries and validated sexual health questionnaires as well as recorded global impression of improvement were used for primary and secondary outcome measures. One thousand five hundred eighty-one women were enrolled in roughly equal numbers for each group. Primary outcomes were more robust for the $100 \mathrm{mg}$ nightly flibanserin dose indicated by significant improvement in SSE scores. Secondary outcomes were significantly improved for all flibanserin doses by sexual health questionnaire measures and significant improvement was noted for the 50 and $100 \mathrm{mg}$ regimens recorded by global impression of improvement over placebo. E-diary desire scores, however, did not show significant improvement for any flibanserin dose. Reported AEs were similar to the Rose trial with discontinuation rates for all flibanserin doses being $13.4 \%$ and placebo being $10.1 \%$.

Also in 2012 the results of Evaluation of the Impact on Sexuality with Evening Treatment (VIOLET) trial were reported. ${ }^{47}$ Similar to DAISY it was a 24 -week prospective randomized placebo controlled double blinded multicenter trial. It compared 50 and $100 \mathrm{mg}$ flibanserin dosed nightly to placebo for safety and efficacy in premenopausal women diagnosed with HSDD in the same fashion as the previous trials. In addition this trial used e-diary, validated sexual health questionnaires and patient global assessment of improvement to assess primary and secondary outcomes.

Eight hundred eighty women equally distributed were enrolled and study characteristics were similar to DAISY. Each flibanserin dose significantly improved the number of SSE and specific measures on sexual health questionnaires as well as global improvement evaluations compared to placebo, however neither dose showed improvement in e-diary scores. Reported AEs were similar to ROSE and DAISY trials. The discontinuation rates due to AEs for placebo, $50 \mathrm{mg}$ flibanserin and $100 \mathrm{mg}$ flibanserin were $3.4 \%, 7.8 \%$ and $11.4 \%$, respectively.

Every Evening of flibanserin versus Placebo in Premenopausal Women with HSDD (BEGONIA) was the last of the phase three 24-week prospective randomized placebo controlled double blinded multicenter trials and was published in 2013.48 BEGONIA compared $100 \mathrm{mg}$ flibanserin each night to placebo in women diagnosed with HSDD in the same fashion previously mentioned. This trial enrolled 1,087 women equally distributed in each group.

It had noted changes in study design from DAISY and VIOLET for inclusion and exclusion as well as the design for outcome measures using only one validated sexual health questionnaire score and SSE for primary outcome measures with secondary outcomes measured with two sexual health questionnaires. It showed significant improvement in primary and secondary outcomes compared to placebo. AEs were similar to ROSE, DAISY and VIOLET with discontinuation rates for placebo and flibanserin as 3.7\% and $9.6 \%$, respectively.

The results of a 52-week flexible dose open label uncontrolled safety and tolerability trial deemed SUNFLOWER were published in 2012. ${ }^{49}$ This trial was developed to 
assess the safety and tolerability of flibanserin and enrolled 1,723 women who completed a previous flibanserin trial. Women were allowed flexible dosing of flibanserin to include $25 \mathrm{mg}$ twice daily, $50 \mathrm{mg}$ twice daily, $50 \mathrm{mg}$ nightly or $100 \mathrm{mg}$ nightly. Dosing adjustments were allowed for tolerability and effectiveness.

Primary outcomes were a measure of known flibanserin AEs, discontinuation due to AEs and serious AEs. Secondary outcomes were measured by changes in validated sexual health questionnaires. Somnolence was the most prevalent AE experienced by $15.8 \%$ of women with all other AEs found in $<8 \%$ of women. The discontinuation rate due to AEs was $10.7 \%$, with serious AEs reported by $1.2 \%$ of women. Secondary end points showed favorable sexual health questionnaire scores.

Flibanserin was first submitted for approval in 2010 based largely on efficacy and safety data of the previously mentioned trials. ${ }^{50}$ However, the FDA felt that the lack of efficacy demonstrated by e-diary data was concerning. In addition the FDA felt that AEs specifically somnolence as well as the effects of alcohol and other commonly used drugs taken with flibanserin were highly concerning. Finally, the FDA felt the trials were too restrictive in their inclusion and exclusion criteria precluding adequate assessment. Flibanserin's approval was initially denied but with recommendations for resubmission.

On August 8, 2015 after resubmission the FDA felt that with restrictions to include risk evaluation management strategies, strong labeling to include a black box warning, and postmarketing studies Flibanserin would fill an unmet need for women with HSDD. Flibanserin ultimately received approval. ${ }^{51}$

\section{Conclusion}

Sexual health and general health go hand in hand and the treatment of sexual dysfunction has global implications on health and wellbeing. Although early researchers tried to conceptualize the sexual response in linear terms, the later researchers have formulated a nonlinear model that seems to much better describe a woman's sexual response. This has led to improved and more accurate definitions for sexual dysfunction and HSDD published in the regularly updated versions of the DSM.

Despite a better female sexual health model and more clear definitions, however, successful treatment options for HSDD remain elusive. Many homeopathic options have been formulated with limited data to support efficacy and until recently the only FDA approved medications to treat sexual dysfunction in women were used off-label. That changed on August 8, 2015 when for the first time the FDA approved flibanserin for treatment of HSDD in premenopausal woman. The authors, in full agreement with the FDA, recognize that with strict adherence to prescribing guidelines flibanserin is now a clear and viable option for an unmet medical need in women.

\section{Disclosure}

Dustie Johnson: Served as a medical liaison with Valeant Pharmaceutical for 6 months.

The authors report no other conflicts of interest in this work.

\section{References}

1. Sexual and Reproductive Health. World Health Organization. Available from: http://www.who.int/reproductivehealth/topics/sexual_health/ sh_definitions/en/. Accessed September 20, 2016.

2. Knoepp LR, Shippey SH, Chen CCG, Cundiff GW, Derogatis LR, Handa VL. Sexual complaints, pelvic floor symptoms, and sexual distress in women over forty. $J$ Sex Med. 2010;7(11):3675-3682.

3. Laumann EO, Paik A, Rosen RC. Sexual dysfunction in the United States: prevalence and predictors. JAMA. 1999;281(6):537-44.

4. American College of Obstetricians and Gynecologists Committee on Practice Bulletins-Gynecology. ACOG practice bulletin No 119: female sexual dysfunction. Obstet Gynecol. 2011;117(4):996-1007.

5. Stahl SM, Sommer B, Allers KA. Multifunctional pharmacology of flibanserin: possible mechanism of therapeutic action in hypoactive sexual desire disorder. $J$ Sex Med. 2011;8:15-27.

6. Freud S. Beyond the Pleasure Principle. London: International psychoanalytical Press; 1922.

7. Masters WH, Johnson VE. Human Sexual Response. Boston: Little, Brown and Company; 1966.

8. Kaplan HS. The New Sex Therapy. New York, NY: Brunner/Mazel; 1974.

9. Kaplan HS. The Illustrated Manual of Sex Therapy. New York, NY: Quadrangle, The New York Times Book Co; 1975.

10. Bullough VL, Bullough B. Human Sexuality: An Encyclopedia. New York, NY and London: Routledge; 2014.

11. Whipple B, Brash-McGreer K. Management of female sexual dysfunction. In: Sipski ML, Alexander CJ, eds. Sexual Function in People with Disability and Chronic Illness. A Health Professional's Guide. Gaithersburg, MD: Aspen Publishers, Inc.; 1997:509-534.

12. Basson R. Using a different model for female sexual response to address women's problematic low sexual desire. J Sex Marital Ther. 2001; 27:395-403.

13. Guay A, Davis SR. Testosterone insufficiency in women: fact or fiction? World J Urol. 2002;20(2):106-110.

14. Traish AM, Kim SW, Stankovic M, Goldstein I, Kim NN. Testosterone increases blood flow and expression of androgen and estrogen receptors in the rat vagina. $J$ Sex Med. 2007;4(3):609-619.

15. Zehr JL, Maestripieri D, Wallen K. Estradiol increases female sexual initiation independent of male responsiveness in rhesus monkeys. Horm Behav. 1998;33(2):95-103.

16. Cappelletii M, Wallen K. Increasing women's sexual desire: the comparative effectiveness of estrogens and androgens. Horm Behav. 2016; 78:178-93

17. Redmond GP. Hormones and sexual function. Int J Fertil Womens Med. 1999;44:193-197.

18. Semmens JP, Wagner G. Estrogen deprivation and vaginal function in postmenopausal women. JAMA. 1982;248(4):445-448. 
19. Gupta P, Özel B, Stanczyk FZ, Felix JC, Mishell DR Jr. The effect of transdermal and vaginal estrogen therapy on markers of postmenopausal estrogen status. Menopause. 2008;15(1):94-97.

20. Simerly RB, Chang C, Muramatsu M, Swanson LV. Distribution of androgen and estrogen receptor mRNA-containing cells in the rat brain: an in situ hybridization study. J Comp Neurol. 1990;294(1):76-95.

21. Pfaus JG. Pathways of sexual desire. J Sex Med. 2009;6(6): 1506-1533.

22. Stahl SM. Targeting circuits of sexual desire as a treatment strategy for hypoactive sexual desire disorder. J Clin Psychiatry. 2010;71: 821-822.

23. Segraves RT, Croft H, Kavoussi R, et al. Bupropion sustained release (SR) for the treatment of hypoactive sexual desire disorder (HSDD) in nondepressed women. J Sex Marital Ther. 2001;27(3):303-316.

24. Meston CM, McCall KM. Dopamine and norepinephrine responses to film-induced sexual arousal in sexually functional and sexually dysfunctional women. J Sex Marital Ther. 2007;303-317.

25. Fava M, Rankin MA, Alpert JE, Nierenberg AA, Worthington JJ. An open trial of oral sildenafilin antidepressant-induced sexual dysfunction. Psychother Psychosom. 1998;67(6):328-331.

26. Nurnberg HG, Lauriello J, Hensley PL, Parker LM, Keith SJ. Sildenafil for iatrogenic serotonergic antidepressant medication-induced sexual dysfunction in 4 patients. J Clin Psychiatry. 1999;60(1):33-35.

27. Liu J, Allgood A, Derogatis LR, et al. Safety and efficacy of low-dose esterified estrogens and methyltestosterone, alone or combined, for the treatment of hot flashes in menopausal women: a randomized, doubleblind, placebo-controlled study. Fertil Steril. 2011;95(1):366-368.

28. Lobo RA, Rosen RC, Yang HM, Block B, Van Der Hoop RG. Comparative effects of oral esterified estrogens with and without methyltestosterone on endocrine profiles and dimensions of sexual function in postmenopausal women with hypoactive sexual desire. Fertil Steril. 2003;79(6):1341-1352.

29. Sherwin BB, Gelfand MM, Brender W. Androgen enhances sexual motivation in females: a prospective, crossover study of sex steroid administration in the surgical menopause. Psychosom Med. 1985;47:339-351.

30. Sherwin BB, Gelfand MM. The role of androgen in the maintenance of sexual functioning in oophorectomized women. Psychosom Med. 1987; 49:397-409.

31. Reis SL, Abdo CH. Benefits and risks of testosterone treatment for hypoactive sexual desire disorder in women: a critical review of studies published in the decades preceding and succeeding the advent of phosphodiesterase type 5 inhibitors. Clinics (Sao Paulo). 2014;69:294-303.

32. Wahlin-Jacobsen S, Pedersen AT, Kristensen E, et al. Is there a correlation between androgens and sexual desire in women? J Sex Med.2015; 12(2):358-373.

33. Clayton AH, McGarvey EL, Warnock JK, et al. Bupropion as a treatment for SSRI-induced sexual dysfunction. Female Sexual Functioning Forum.; 2000 Oct 26-29; Boston (MA).

34. Gitlin MJ. Effects of depression and antidepressants on sexual functioning. Bull Menninger Clin. 1995;59(2):232-248.

35. Salerian AJ, Deibler WE, Vittone BJ, et al. Sildenafil for psychotropicinduced sexual dysfunction in 31 women and 61 men. $J$ Sex Marital Ther. 2000;26(2):133-140.

36. Norden MJ. Buspirone treatment of sexual dysfunction associated with selective serotonin re-uptake inhibitors. Depression. 1994;2: 109-112.

37. Landén M, Eriksson E, Agren H, Fahlén T. Effect of buspirone on sexual dysfunction in depressed patients treated with selective serotonin reuptake inhibitors. J Clin Psychopharmacol. 1999;19(3):268-271.

38. Othmer E, Othmer SC. Effect of buspirone on sexual dysfunction in patients with generalized anxiety disorder. J Clin Psychiatry. 1987;48(5): 201-203.

39. Presentation at Meeting of the FDA Advisory Committee for Reproductive Health Drugs; June 18, 2010; Available from: http://www.fda.gov/ downloads/advisorycommittees/committeesmeetingmaterials/drugs/ reproductivehealthdrugsadvisorycommittee/ucm248751.pdf. Published June 18, 2010. Accessed October 1, 2016
40. Popova NK, Amstislavskaya TG. Involvement of the 5-HT (1A) and 5-HT (1B) serotonergic receptor subtypes in sexual arousal in male mice. Psychoneuroendocrinology. 2002;27(5):609-618.

41. Invernizzi RW, Sacchetti G, Parini S, Acconcia S, Samanin R. Flibanserin, a potential antidepressant drug, lowers 5-HT and raises dopamine and noradrenaline in the rat prefrontal cortex dialysate: role of 5-HT1A receptors. Br J Pharmacol. 2003;139(7):1281-1288.

42. Sang JH, Kim TH, Kim SA. Flibanserin for Treating Hypoactive Sexual Desire Disorder. J Menopausal Med. 2016;22(1):9-13.

43. Kennedy S. Flibanserin: initial evidence of efficacy on sexual dysfunction, in patients with major depressive disorder. J Sex Med. 2010;7(10): 3449-3459.

44. Stahl SM, Sommer B, Allers KA. Multifunctional pharmacology of flibanserin: possible mechanism of therapeutic action in hypoactive sexual desire disorder. J Sex Med. 2011;8(1):15-27.

45. Goldfischer ER, Breaux J, Katz M, et al. Continued efficacy and safety of flibanserin in premenopausal women with Hypoactive Sexual Desire Disorder (HSDD): results from a randomized withdrawal trial. $J$ Sex Med. 2011;8:3160-3172.

46. Thorp J, Simon J, Dattani D, et al; DAISY Trial Investigators. Treatment of hypoactive sexual desire disorder in premenopausal women: efficacy of flibanserin in the DAISY study. $J$ Sex Med. 2012;9(3):793-804.

47. Derogatis LR, Komer L, Katz M, et al; VIOLET Trial Investigators. Treatment of hypoactive sexual desire disorder in premenopausal women: efficacy of flibanserin in the VIOLET Study. J Sex Med. 2012; 9(4):1074-1085.

48. Katz M, DeRogatis LR, Ackerman R, et al; BEGONIA Trial Investigators. Efficacy of flibanserin in women with hypoactive sexual desire disorder: results from the BEGONIA trial. $J$ Sex Med. 2013;10(7): $1807-1815$.

49. Jayne C, Simon JA, Taylor LV, Kimura T, Lesko LM; SUNFLOWER Study Investigators. Open-label extension study of flibanserin in women with hypoactive sexual desire disorder. J Sex Med.2012;9(12): 3180-3188.

50. FDA News Release. U.S. Food \& Drug. Available from: http://www. fda.gov/downloads/advisorycommittees/committeesmeetingmaterials/ drugs/drugsafetyandriskmanagementadvisorycommittee/ucm 449088 . pdf. Accessed September 28, 2016.

51. US Food and Drug. FDA Briefing Document. US Food and Drug. Available from: https://www.fda.gov/NewsEvents/Newsroom/PressAnnouncements/ucm458734.htm. Accessed September 28, 2016.

52. Zestra Publication. Zestra. Available from: http://www.zestra.com/ about/clinical-evidence/index.php. Accessed September 29, 2016.

53. Alura. Alura. Available from: http://www.femalelibido.com/alura/. Accessed September 29, 2016.

54. EWIRE. Introducing All-Natural PROSENSUAL ${ }^{\circledR}$; The Only Topical Sexually Stimulating Personal Lubricant. Available from: http:// www.ewire.com/news-releases/introducing-all-natural-prosensual-the-only-topical-sexually-stimulating-personal-lubricant/. Accessed September 28, 2016

55. Durex USA [homepage on the Internet]. Available from: http://www. durexusa.com. Accessed September 28, 2016.

56. Ito TY, Trant AS, Polan ML. A double-blind placebo-controlled study of ArginMax, a nutritional supplement for enhancement of female sexual function. $J$ Sex Marital Ther. 2001;27(5):541-549.

57. Avlimil. Available from: https://www.avlimil.com/Index.aspx. Accessed September 28, 2016.

58. Phillips E, Bauman C. Safety surveillance of esterified estrogensmethyltestosterone (Estratest and Estratest HS) replacement therapy in the United States. Clin Ther. 1997;19(5):1070-1084.

59. Clayton AH, Maserejian NN, Connor MK, Huang L, Heiman JR, Rosen RC. Depression in premenopausal women with HSDD: baseline findings from the HSDD Registry for Women. Psychosom Med. 2012;74(3): 305-311. 
International Journal of Women's Health

Dovepress

\section{Publish your work in this journal}

The International Journal of Women's Health is an international, peerreviewed open-access journal publishing original research, reports, editorials, reviews and commentaries on all aspects of women's healthcare including gynecology, obstetrics, and breast cancer. The manuscript management system is completely online and includes Visit http://www.dovepress.com/testimonials.php to read real quotes from published authors.

Submit your manuscript here: http://www.dovepress.com/international-journal-of-womens-health-journal 